\title{
Волоконно-оптические сенсоры на основе особо чистых халькогенидных стекол
}

В.С. Ширяев, д.х.н. ${ }^{7}$, А. П. Вельмужов, к. х. н. ${ }^{1}$, Э. В. Караксина, д. х. н. ${ }^{1}$, Т.В. Котерева, к. х. н.' , Б. С. Степанов, К. Х. н. ${ }^{1}$, Е. В. Бойко, К. Т. н. ${ }^{2}$

УДК 681.586 .5

\begin{abstract}
Представлены экспериментальные результаты по разработке волоконных сенсоров на основе пассивных и активных световодов из особо чистых халькогенидных стекол для изучения химического состава жидкостей методом эванесцентной ИК-спектроскопии. Изготовлены источники спонтанного излучения диапазона 1-9 мкм на основе халькогенидных световодов, легированных ионами редкоземельных элементов, с высокими эмиссионными свойствами. На основе пассивных халькогенидных световодов разработаны и созданы новые типы высокочувствительных волоконных сенсорных элементов. Проведены успешные испытания различных халькогенидных световодов для анализа нефтепродуктов и объектов окружающей среды.
\end{abstract}

Ключевые слова: эванесцентная ИК-спектроскопия, волоконный световод, халькогенидное стекло, сенсорный элемент, редкоземельный элемент

The paper presents experimental results on the development of fiber sensors based on passive and active optical fibers made of especially pure chalcogenide glasses for studying the chemical composition of liquids by evanescence IR spectroscopy. Spontaneous emission sources of the 1-9 $\mu \mathrm{m}$ spectral range based on REE-doped chalcogenide glass fibers with high emission properties were manufactured. On the basis of passive chalcogenide fibers, novel types of high-sensitive fiber sensor elements have been developed and created. various chalcogenide fibers have been successfully tested for the analysis of petroleum products and environmental objects.

Keywords: evanescence IR spectroscopy, optical fiber, chalcogenide glass, sensor element, rare earth element

\section{Введение}

Волоконная спектроскопия затухающей волны (FEWS - fiber evanescent wave spectroscopy) среднего инфракрасного диапазона - интенсивно

1 Институт химии высокочистых веществ им. Г. Г. Девятых РАН, Нижний Новгород, ул. Тропинина, 49.

2 Нижегородский государственный университет им. Н. И. Лобачевского, НИИ химии, Нижний Новгород, пр. Гагарина, 23.

shiryaev@ihps-nnov.ru. развивающийся метод анализа. Другое его название - волоконная спектроскопия многократно нарушенного полного внутреннего отражения (МНПВО). Этот метод может применяться для контроля технологических процессов на производстве (в газовой и нефтяной промышленности, при изготовлении продуктов питания, лекарств); мониторинга загрязнения окружающей среды на производствах и в городах; обнаружения взрывоопасных, наркотических и отравляющих веществ (в аэропортах, метро и других местах массового скопления 
людей); в медицине (диагностика различных, в том числе онкологических, заболеваний человека и животных на ранних стадиях по анализу крови, выдыхаемого воздуха, тканей, органов); для определения качества продуктов питания по выделяющимся газообразным продуктам гниения (метан, аммиак, сероводород); в бактериологическом анализе и др. [1-5].

FEWS-метод основан на регистрации спектра поглощения волоконного световода, погруженного в анализируемую жидкость (газ, порошок). За счет частичного выхода излучения за границы световода, в спектре проявляются полосы селективного поглощения компонентов аналита. Основное преимущество метода заключается в возможности дистанционного исследования образцов вне спектрометра, что позволяет проводить анализ веществ непосредственно в исследуемой системе без дополнительного отбора пробы. Когда растворитель эффективно поглощает излучение, методы отражения становятся единственно возможными для проведения ИК-спектроскопического анализа. В спектральном диапазоне 3-15 мкм присутствуют полосы поглощения большинства органических и неорганических функциональных групп (насыщенные, ненасыщенные, ароматические углеводороды, кетоны, альдегиды, алкил, карбоксил, карбонил, аминогруппы и др.). В среднем ИК-диапазоне спектры поглощения даже структурно близких гомологов органических веществ надежно отличаются друг от друга. Это позволяет анализировать большое количество веществ и их смесей, в том числе нефтепродуктов, объектов окружающей среды и биологических образцов. Основные материалы для изготовления волоконных сенсоров МНПвО-спектроскопии - халькогенидные стекла и твердые растворы на основе галогенидов серебра [1-5].

По сравнению с волоконными сенсорами на основе твердых растворов галогенидов серебра халькогенидные сенсоры обладают значительно лучшими химической и фотоустойчивостью, чувствительностью, а также повышенным сроком эксплуатации. Волоконные сенсоры на основе селенидных и теллуридных стекол имеют низкие оптические потери в спектральном диапазоне 2-15 мкм [6, 7] и высокую химическую стойкость к агрессивным средам (вода, органические растворители, концентрированная плавиковая кислота, разбавленные растворы минеральных кислот). Эффективными источниками излучения среднего ИК-диапазона могут быть активные волокна из халькогенидных стекол, легированных Р3Э, у которых наблюдаются широкополосные спектры люминесценции в диапазоне длин волн 1-9 мкм с достаточно высокой выходной мощностью $[8,9]$.

Цель работы состояла в разработке волоконнооптических сенсоров на основе особо чистых халькогенидных стекол для FEWS-спектроскопии среднего ИК-диапазона. Приведены примеры использования таких сенсоров для анализа нефтепродуктов и объектов окружающей среды.

\section{Экспериментальная часть}

Для изготовления бесструктурных (без стеклянной отражающей оболочки) оптических волокон для FEWS-сенсоров использовали особо чистые стекла состава $\mathrm{Ge}_{20} \mathrm{Se}_{80}, \mathrm{Ge}_{20} \mathrm{Se}_{70} \mathrm{Te}_{10}, \mathrm{Ge}_{10} \mathrm{As}_{30} \mathrm{Se}_{38} \mathrm{Te}_{22}$ и $\mathrm{Ge}_{28} \mathrm{Sb}_{12} \mathrm{Se}_{60}$. Стекла получали плавлением простых веществ в вакуумированных кварцевых ампулах. Для снижения содержания примесей проводили химикодистилляционную очистку стеклообразующего расплава [10]. Стекло $\mathrm{Ge}_{20} \mathrm{Se}_{80}$ было получено через моноселенид германия по методике, разработанной авторами ранее [11]. Минимальное содержание примесей в стеклах составило: водород - 3 ppm (ат), кислород - 0,2 ppmw (мг/кг), углерод - 3 ppmw, $\mathrm{Si}-0,5$ ppmw. Световоды вытягивали тигельным методом. Оптические потери в волокне $\mathrm{Ge}_{20} \mathrm{Se}_{80}$ не превышали 1 дБ/м в спектральном диапазоне 5,0-7,8 мкм; в волокне $\mathrm{Ge}_{26} \mathrm{As}_{17} \mathrm{Se}_{25} \mathrm{Te}_{32}-0,7$ дБ/ м в диапазоне 5,5-8, 5 мкм. Для создания источников инфракрасного излучения изготовили световоды из стекол систем $\mathrm{Ga}(\mathrm{In})-\mathrm{Ge}-\mathrm{As}(\mathrm{Sb})-\mathrm{Se}$, легированных $\mathrm{Pr}, \mathrm{Dy}$ и Tb на уровне 500-2600 ppm. Стекла получали многостадийным способом, который включал химическую дистилляционную очистку расплава и загрузку галлия и индия методом селективных химических транспортных реакций $[12,13]$. Активные волокна вытягивали методом двойного тигля. В качестве оболочки использовали особо чистые стекла системы Ge-As-S. Минимальные оптические потери активных волокон находились в пределах 0,8-1,0 дБ/м. Спектры люминесценции легированных стекол и волокон регистрировали при комнатной температуре с помощью ИК-фурье-спектрометра, оснащенного охлаждаемым жидким азотом InSb-детектором и оптическим фильтром с длиной волны отсечки 3 мкм. Для накачки использовали лазеры, работающие в непрерывном режиме, с длинами волн излучения 1,56 и 1,97 мкм. Полученные источники на основе халькогенидных стекол позволяли проводить FEWS-анализ веществ, поглощающих в спектральных диапазонах 2-3, 4-6, и 7-8 мкм, соответствующих полосам люминесценции Р3Э. 


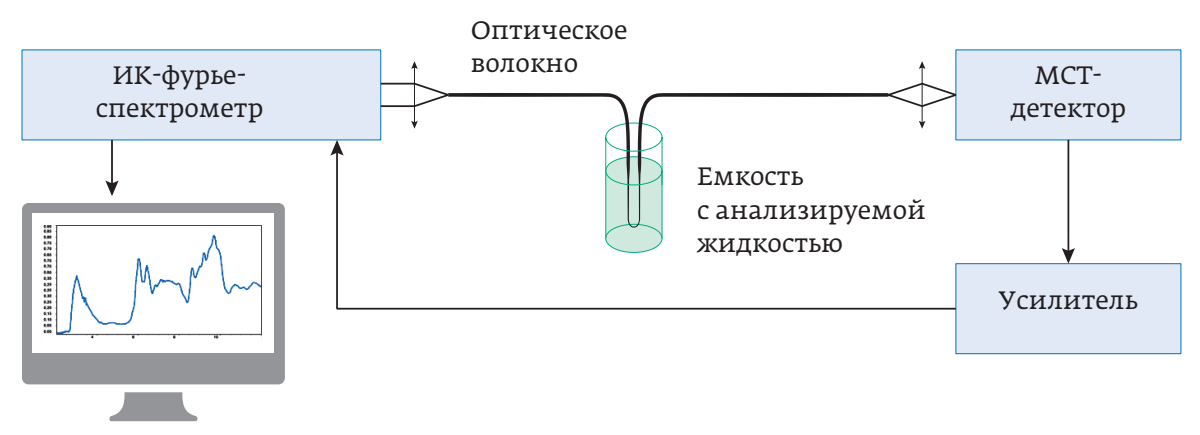

Puc. 1. Принципиальная схема установки для проведения FEWS-анализа к ИК-фурье-спектрометру с помощью систем линз (рис. 1); волоконный сенсор в корпусе, подключенный к ИК-фурьеспектрометру через зондовую приставку (рис. 2); волоконный сенсор с источником излучения из легированного Р3Э халькогенидного световода (рис. 3). Сенсор в корпусе состоял из чувствительного элемента, подводящего и отводящего волокон (см. рис. 2). Корпус изготавливали из полиэфирэфиркетона
Из полученных световодов изготовлены волоконные сенсоры с различной геометрией чувствительной зоны: линейный участок постоянного диаметра; участок с биконической перетяжкой; участок в форме одной, двух и трех петель. Для образования петли волоконный световод изгибали вокруг керамического стержня, нагреваемого изнутри и обдуваемого особо чистым аргоном. Радиус изгиба волокна составил 2 мм. Перетяжки (области уменьшения диаметра) получали растяжением волокна при нагревании с использованием двух высокоточных позиционеров (Zaber Inc.).

Для проведения FEWS-анализа жидкостей использовали три типа конструкций оптической системы: волоконный сенсор, подключенный

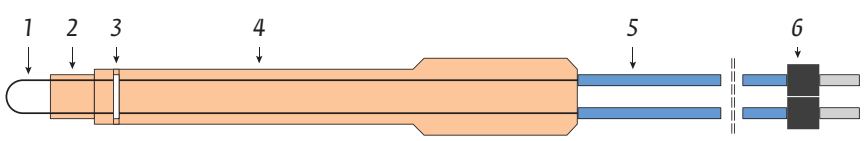

a)

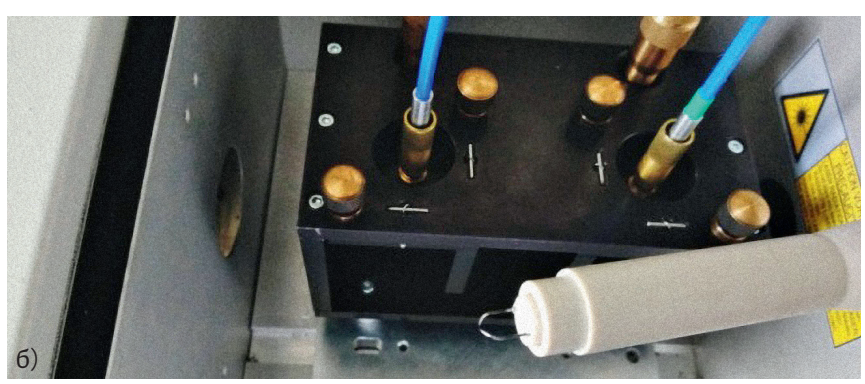

Puс. 2. Волоконно-оптический сенсор в корпусе. а - схема сенсора: 1 - U-образный чувствительный элемент (волокно); 2 - съемный наконечник; 3 - область стыковки сенсора с подводящим и отводящим волокнами; 4 - корпус из PЕЕК; 5 - подводящее и отводящее волокна в защитных полимерных трубках; 6 - SMA 905 оптические коннекторы, 6-фотография сенсора, подключенного к зондовой приставке ИК-фурье-спектрометра
(PEЕК) как одного из наиболее термически, механически и химически стойкого полимерного материала. Конструкция волоконного сенсора позволяла многократно отсоединять чувствительный элемент для его очистки или замены. В качестве подводящего и отводящего волокон использовали многомодовый световод из стекла системы As-Se-Te с соотношением диаметров сердцевины и оболочки 400 / 490 мкм с оптическими потерями 0,05-0,1 дБ/м в диапазоне 2-9 мкм. Для подключения сенсора к зондовой приставке ИК-фурьеспектрометра использовали оптические коннекторы стандарта SMA 905.

Люминесценцию легированного халькогенидного световода использовали в качестве источника инфракрасного излучения для волоконного сенсора (рис. 3). Экспериментальная установка включала емкость с анализируемой жидкостью, в которую погружали сенсор в виде бесструктурного волокна на основе стекол $\mathrm{Ce}_{20} \mathrm{Se}_{80}$ и $\mathrm{Ge}$-(As)-Se-Te с различной геометрией чувствительной зоны. Излучение, возникающее в легированном световоде, заводили в сенсор. Выходящий из сенсора сигнал регистрировали МСТ-детектором ИК-фурьеспектрометра.

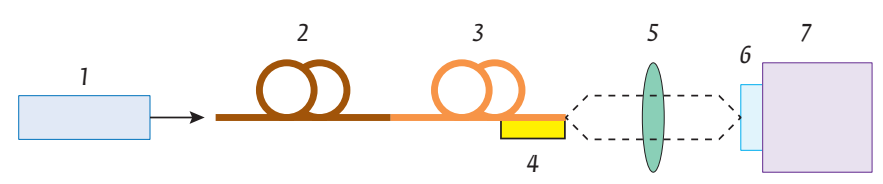

Puc. 3. Схема установки для записи спектров веществ, погпощающих в области изиучения ионов $\operatorname{Pr}(3+)$ : 1 - эрбиевый пазер (1560 нм); 2 - активный халькогенидный световод; 3 - бесструктурный световод из стекиа $\mathrm{Ge}_{20} \mathrm{Se}_{80}$ (Ge-(As)-Se-Te); 4 - чашка Петри с аналитом; 5 - фокусирующая пинза из ZnSe; 6 - оптический фильтр; 7-ИК-фурье-спектрометр 


\section{Результаты и обсуждение}

Волоконные сенсорные элементы на основе пассивных халькогенидных световодов

Разработанные способы получения особо чистых халькогенидных стекол позволяют существенно снизить содержание примесей, поглощающих в спектральных диапазонах 4-5 и 8-10 мкм и, как следствие, улучшить целевые характеристики волоконных сенсоров (уровень и диапазон оптической прозрачности). Изготовленные халькогенидные FEWS-сенсоры были протестированы для анализа химического состава различных жидкостей. Преимущество световода из стекла $\mathrm{Ge}_{10} \mathrm{As}_{30} \mathrm{Se}_{38} \mathrm{Te}_{22}$ в качестве чувствительного элемента заключается в более широкой области пропускания (2-15 мкм) по сравнению с волокном из $\mathrm{Ge}_{20} \mathrm{Se}_{80}$ (2-10 мкм). Световод из $\mathrm{Ge}_{28} \mathrm{Sb}_{12} \mathrm{Se}_{60}$ с тем- $^{-}$ пературой стеклования $285^{\circ} \mathrm{C}$ перспективен для FEWS-анализа при повышенных температурах (исследование экзотермических реакций, контроль качества моторного масла в работающем двигателе и др.). Датчики из халькогенидного волокна показали высокую воспроизводимость результатов измерений в течение нескольких месяцев эксплуатации.

С использованием волоконного световода $\mathrm{Ce}_{20} \mathrm{Se}_{80}$ с различной формой чувствительной зоны зарегистрированы спектры поглощения гидроочищенного дизельного топлива. В спектрах обнаружены и идентифицированы более 20 полос поглощения. Положение и соотнесение наиболее интенсивных полос поглощения приведены в табл. 1. Спектры поглощения дизельного топлива в области 2800-3000 см-1, зарегистрированные с помощью

Таблица 1. Полосы поглощения, обнаруженные в ИК-спектрах гидроочищенного дизельного топиива

\begin{tabular}{|c|c|c|}
\hline $\begin{array}{c}\text { Положение полосы, } \\
\text { см }^{-1}\end{array}$ & $\begin{array}{l}\text { Площадь, } \\
\text { отн. ед. }\end{array}$ & Тип колебания \\
\hline $1125-1171$ & 0,04 & Ароматич. \\
\hline 1371 & 0,06 & $\delta\left(\mathrm{C}\left(\mathrm{CH}_{3}\right)_{2}\right)$ \\
\hline 1378 & 0,05 & $\delta\left(-\mathrm{CH}_{3}\right)$ \\
\hline 1455 & 0,29 & $\delta_{\mathrm{as}}\left(-\mathrm{CH}_{3}\right)$ \\
\hline 1462 & 0,90 & $\left.\delta\left(-\mathrm{CH}_{2}\right)^{-}\right)$ \\
\hline 1606 & 0,05 & Ароматич. \\
\hline 2855 & 0,43 & $\mathrm{v}_{\mathrm{s}}\left(-\mathrm{CH}_{2}-\right)$ \\
\hline 2874 & 0,06 & $v_{s}\left(-C_{3}\right)$ \\
\hline 2913 & 1,00 & $v_{\text {as }}\left(-\mathrm{CH}_{2}-\right)$ \\
\hline 2925 & 0,35 & $\mathrm{~V}_{\mathrm{as}}\left(-\mathrm{CH}_{2}-\right)$ \\
\hline 2955 & 0,49 & $v_{a s}\left(-\mathrm{CH}_{3}\right)$ \\
\hline
\end{tabular}

сенсоров с различной геометрией чувствительной зоны, представлены на рис. 4. При переходе от линейной формы сенсора к двойной петле интегральная интенсивность собственных полос поглощения дизельного топлива возрастает на порядок. Это обусловлено возбуждением высших мод при изгибе оптического волокна. Теоретические расчеты показали, что моды высших радиальных порядков имеют большие коэффициенты затухания, так как излучение глубже проникает в поглощающую среду [14]. Наряду с изгибом чувствительной зоны, возбуждение высших мод в сенсоре может достигаться изготовлением перетяжки или введением излучения под углом к торцу сенсора. Это позволяет повысить на порядок уровень полезного сигнала.

Разработана методика FEWS-определения содержания присадки в дизельном топливе. Измерения проводили с использованием волоконного световода из стекла $\mathrm{Ce}_{10} \mathrm{As}_{30} \mathrm{Se}_{38} \mathrm{Te}_{22}$ с U-образной формой чувствительной зоны. Добавление присадки приводит к появлению в спектрах достаточно интенсивных полос поглощения, не перекрывающихся с полосами основного вещества (рис. 5а). Эти полосы соответствуют карбоксильным группам (1749 см $\left.{ }^{-1}\right)$, карбоксилатаниону $\left(1636 \mathrm{~cm}^{-1}\right)$ и сложным эфирам (1240 и $\left.1276 \mathrm{~cm}^{-1}\right)$. Полосы поглощения сложных эфиров были использованы для количественного определения присадки в дизельном топливе. На рис. $5 б$ приведена зависимость интегральной интенсивности полосы поглощения в области $1240 \mathrm{~cm}^{-1}$ от концентрации присадки

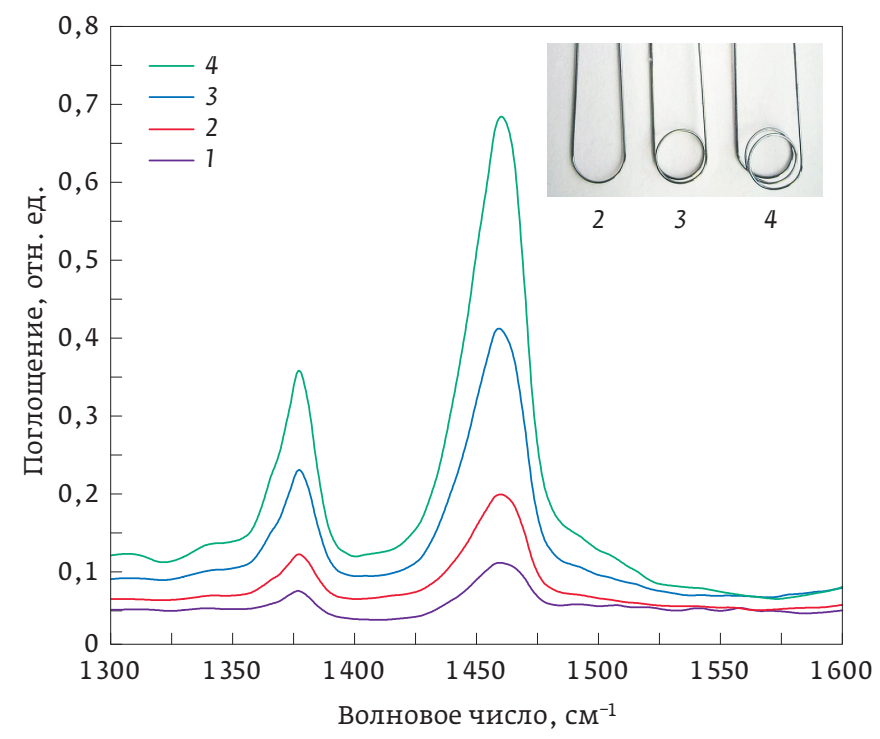

Puc. 4. Спектры погпощения дизельного топлива, полученные с помощью волоконных сенсоров с разиччной геометрией чувствительной зоны: 1 - прямой участок; 2 - U-образный; 3 - две петли; 4 - три петли 

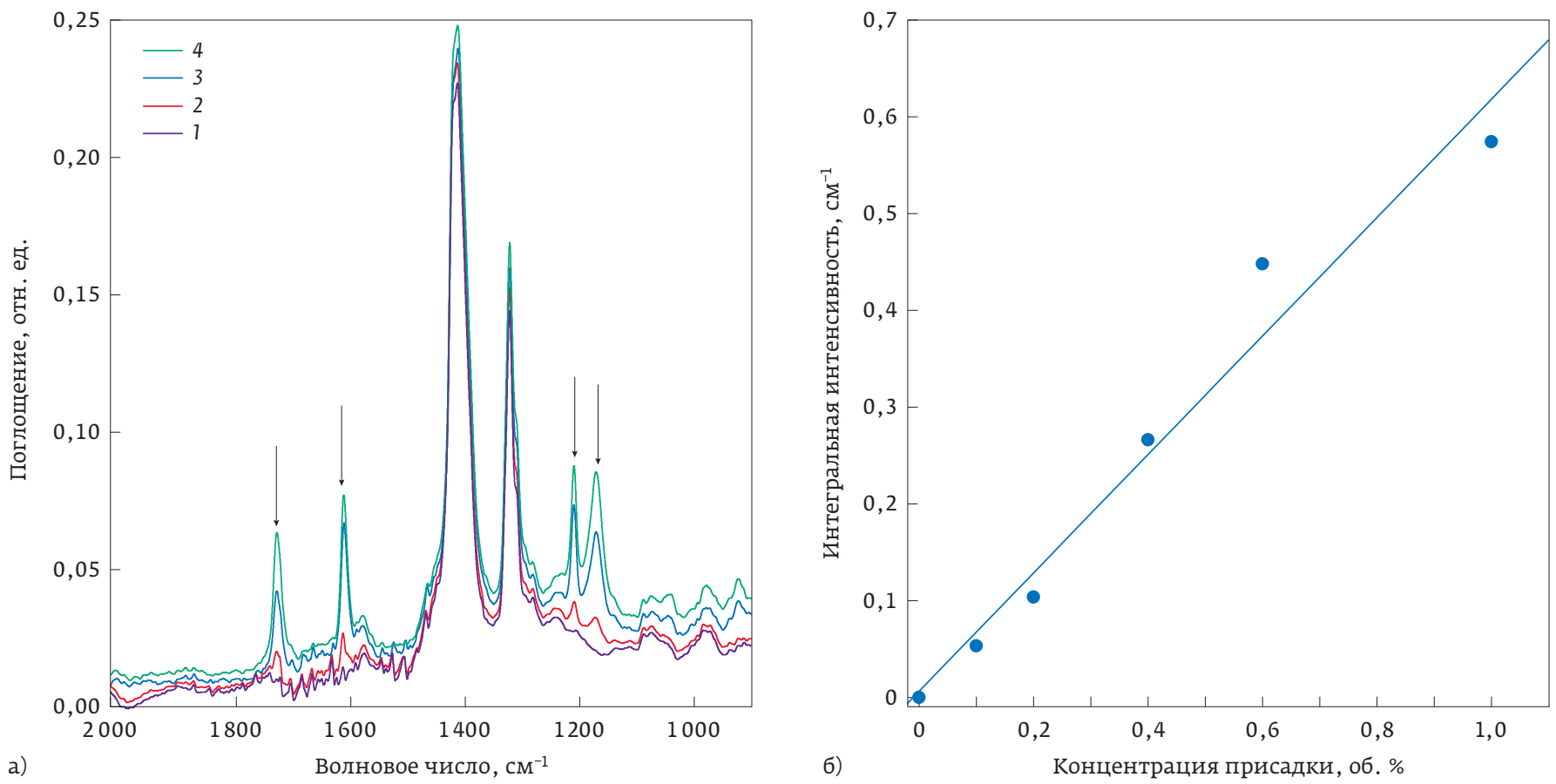

Puc. 5. а-спектры поглощения дизельного топлива с присадкой, полученные с помощью сенсора с U-образной формой чувствительной зоны: 1 - топливо без присадки; 2 - 0,2 об. \% присадки; 3- 0,6 об. \% присадки; 4 - 1 об. \% присадки; 6- зависимость интегральной полосы поглощения в области $1276 \mathrm{~cm}^{-1}$ от концентрации присадки. Полосы поглощения, обусловленные наличием присадки, отмечены стрелками

в диапазоне 0-1,0 об. \%. Предел обнаружения присадки в дизельном топливе составил 0,02 об. \% при рекомендуемой производителями концентрации 0,05-1,0 об. \% в зависимости от условий работы двигателя. Случайная погрешность определения присадки составила не более $10 \%$ в указанном концентрационном интервале при доверительной вероятности 0,95 .

Проведены испытания халькогенидных волоконных сенсоров в полимерном корпусе для анализа жидкостей технологических производств. Измерение поглощения излучения в среднем ИК-диапазоне в жидкостях представляет собой сложную задачу, поскольку зачастую взаимное влияние функциональных групп реальных объектов мешает идентификации и количественному определению представляющих интерес показателей. Исследованы растворы моноэтаноламина (МЭА), метилдиэтаноламина (МДЭА), гидразина, образцы сточных вод из шламохранилищ и машиностроительных предприятий. Водные растворы МЭА и МДЭА используются на нефтеперерабатывающих заводах в качестве абсорбентов для очистки сероводородсодержащих углеводородных газов. Установка халькогенидных волоконных сенсоров в колоннах сорбционной очистки газов (или дизельного топлива), которые способны оперативно проводить дистанционный мониторинг параметров газонасыщенности абсорбционного раствора и измерение концентрации свободных аминов, обеспечит автоматизацию и строгое соблюдение

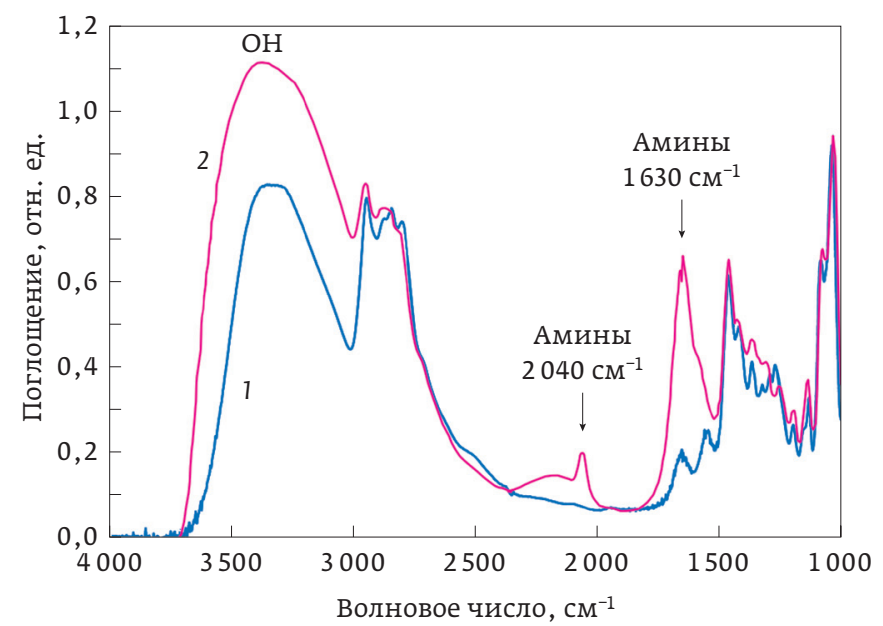

Puс. 6. Спектры поглощения, полученные с помощью халькогенидных волоконных сенсоров:

1-40\%-ный раствор МДЭА, 2 - 30\%-ный раствор МДЭА, насыщенный 1,25\% сероводорода 
режима технологического процесса. Исследованы образцы 40\%-ного раствора МДЭА и 30\%-ного МДЭА, насыщенного 1,25\% сероводорода (рис. 6). Спектры поглощения содержат широкую полосу в области 3300-3400 $\mathrm{cm}^{-1}$, обусловленную валентными колебаниями ОН-групп спиртов, связанных межмолекулярными водородными связями. Полосы поглощения 1630 и $2040 \mathrm{~cm}^{-1}$ появляются для аминов в форме солей, в которые они переходят при взаимодействии с кислыми газами. Концентрации ОН-групп и солей аминов показывают количество МДЭА, связанного с сероводородом и другими кислыми газами (степень насыщения) и свободного, остающегося в растворе в качестве абсорбента. Использование волоконного сенсора позволит проводить контроль технологических процессов при очистке природного газа.

Источники излучения среднего ИК-диапазона на основе активированных халькогенидных световодов

Световоды, легированные Р3Э, проявляли интенсивную широкополосную люминесценцию в средней ИК-области (рис. 7) и выдерживали непрерывное лазерное излучение накачки на длинах волн
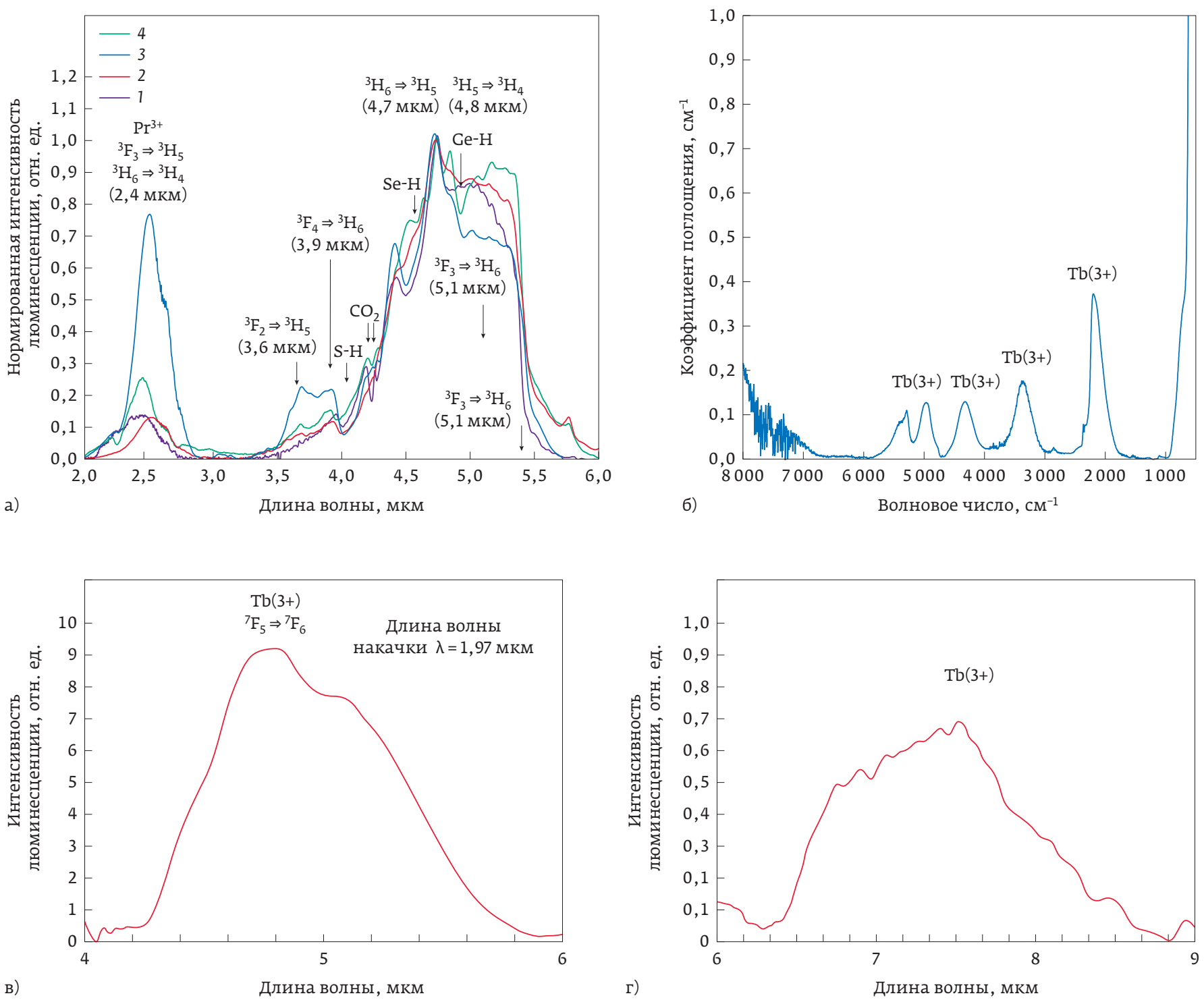

Puc. 7. а-нормированные эмиссионные спектры двухслойных легированных световодов:

1-2000 ppm Pr(3+)-Ge ${ }_{76.5} \mathrm{As}_{16.5} \mathrm{Se}_{62.5} \mathrm{In}_{3} \mathrm{I}_{3} / \mathrm{Ge}_{2} A s_{39} \mathrm{~S}_{59} ; 2-2600 \mathrm{ppm} \operatorname{Pr}(3+)-G e_{16.5} \mathrm{As}_{16.5} \mathrm{Se}_{62.5} \mathrm{In}_{3} \mathrm{I}_{3} / \mathrm{Ge}_{2} \mathrm{As}_{39} \mathrm{~S}_{59}$;

3-500 ppm Pr(3+)-Ga $\mathrm{Ge}_{16} \mathrm{As}_{17} \mathrm{Se}_{64} / \mathrm{As}_{2} \mathrm{~S}_{3} ; 4-1300$ ppm $\operatorname{Pr}(3+)-\mathrm{Ga}_{3} \mathrm{Ge}_{31} \mathrm{As}_{18} \mathrm{Se}_{48} / \mathrm{Ge}_{18} \mathrm{As}_{22} \mathrm{~S}_{60}$;

6- спектр поглощения стекиа 1300 ppm Tb(3+)-Ga-Ge-As-Se; в, z - спектры эмиссии стекла Tb(3+)-Ga-Ge-As-Se 


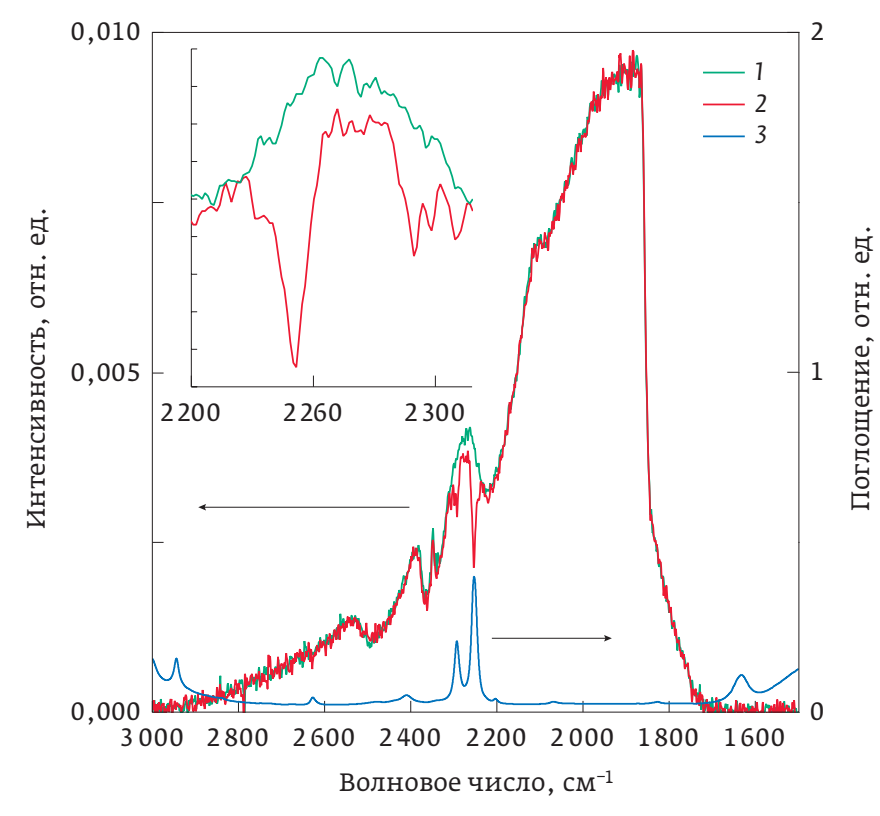

Pис. 8. Спектры излучения на выходе пассивного бесструктурного световода из $\mathrm{Ge}_{20} \mathrm{Se}_{80}$ (3 на рис. 3) nри использовании волокна, легированного празеодимом, в качестве источника излучения (2 на рис. 3): 1 - пассивный световод находится на воздухе, 2 - пассивный световод помещен в ацетонитрии, 3 - спектр поглощения ацетонитрила

1,56 и 1,97 мкм при входной мощности до 1,6 Вт без принудительного охлаждения. Оптические характеристики активных волокон позволили разработать и реализовать на их основе экспериментальную схему идентификации органических соединений и количественного анализа в полностью волоконном исполнении (рис. 3) [15]. Спектры поглощения ацетонитрила, для регистрации которых в качестве источника излучения использовали волокно, легированное празеодимом, приведены на рис. 8. Поглощение излучения ацетонитрилом, в который был погружен волоконный сенсор, приводит к уменьшению интенсивности люминесценции ионов празеодима в области 2291 и $2254 \mathrm{~cm}^{-1}$. Изготовление перетяжки дало возможность повысить чувствительность измерений в 1,5 раза. Увеличение мощности накачки эрбиевого лазера от 0,5 до 1,5 Вт при сохранении интенсивности полос поглощения ацетонитрила приводит к существенному снижению уровня шума. Это позволит снизить пределы обнаружения при разработке количественного анализа веществ .

Преимуществами предложенной оптической системы (рис. 3) является высокая стабильность оптических параметров, селективность и существенно меньшая стоимость по сравнению с сенсорами, подключаемыми к ИК-фурье-спектрометру. Подобная схема была реализована ранее, например, с помощью волоконного световода из стекла $\mathrm{Ga}_{5} \mathrm{Ge}_{20} \mathrm{Sb}_{10} \mathrm{~S}_{65}$, легированного диспрозием [16, 17]. Отличительная особенность предложенной схемы состоит в использовании в качестве источника излучения и сенсора двух волокон различного химического состава $\left(\mathrm{Ce}_{26} \mathrm{As}_{17} \mathrm{Se}_{25} \mathrm{Te}_{32}+\operatorname{Pr}\right.$ и $\mathrm{Ce}_{20} \mathrm{Se}_{80}$, соответственно). Среди ряда преимуществ отметим возможность многократного использования дорогостоящего люминесцирующего волокна при замене короткого участка пассивного волокна, погружаемого в анализируемый раствор и выполняющего роль сенсора.

Для создания полностью волоконной сенсорной системы, другим альтернативным источником излучения среднего ИК-диапазона может быть генератор суперконтинуума (CK). За последнее десятилетие достигнут значительный прогресс в получении генераторов СК среднего ИК-диапазона на основе халькогенидных световодов [18-20].

\section{Заключение}

Изготовлены волоконные сенсоры на основе халькогенидных световодов для исследования химического состава жидких растворов методом FEWS-спектроскопии. Разработана полностью волоконная оптическая система с использованием в качестве источника с широким спектром излучения люминесцирующего халькогенидного световода. Проведены успешные испытания халькогенидных световодов в сенсорных системах для определения химического состава нефтепродуктов и объектов окружающей среды.

Спектр применения волоконно-оптических сенсоров, представленных в работе, очень широкий. Хорошие перспективы применения в нефте- и газодобывающей, а также перерабатывающей промышленности, пищевой индустрии и разработке медицинского оборудования и др.

\section{Литература / References}

1. Boussard-Pledel C. Chalcogenide waveguides for infrared sensing. In the book Chalcogenide glasses: preparation, properties and applications. Editors: Adam J.-L. and Zhang X. // Woodhead Publishing Series in Electronic and Optical Materials. Oxford Cambridge Philadelphia New Delhi. 2014. No. 44. PP. 381-410 (607 p.).

2. Jiang X., Jha A. Engineering of a $\mathrm{Ge}-\mathrm{Te}-\mathrm{Se}$ glass fibre evanescent wave spectroscopic (FEWS) mid-IR chemical sensor for the analysis of food and pharmaceutical products // Sensors and Actuators B: Chemical. 2015. V. 206. PP. 159-169. https://doi.org/10.1016/j.snb.2014.09.022.

3. Raichlin Y., Katzir A. Fiber-Optic Evanescent Wave Spectroscopy in the Middle Infrared // Applied Spectroscopy. 2008. V. 62 (2). PP. 55A-72A.

4. Artyushenko V., Bocharnikov A., Sakharova T. and Usenov I. Midinfrared Fiber Optics for 1-18 $\mu \mathrm{m}$ Range: IR-fibers and waveguides for 
laser power delivery and spectral sensing // Optics \& Photonics. 2014 V. 4. PP. 35-39.

5. Sanghera J. S., Kung F.H., Busse L.E., Pureza P.C., Aggarwal I. D. Infrared Evanescent Absorption Spectroscopy of Toxic Chemicals Using Chalcogenide Glass Fibers // Journal of American Ceramic Society. 1995. V. 78 (8). PP. 2198-2202.

6. Чурбанов М.Ф., Ширяев В.С. Высокочистые халькогенидные стекла для волоконной оптики // Высокочистые вещества. - М.: Научный мир, 2018. С. 817-851 (994 с.).

Churbanov M.F., Shiryaev V.S. High-purity chalcogenide glasses for fiber optics. PP. 817-851. Chapter in the book High-purity substances. Moscow, Nauchnyj mir Publ. 2018. 994 p.

7. Shiryaev V.S., Churbanov M.F., Snopatin G.E., Chenard F. Preparation of low loss core-clad As-Se glass fibers // Optical Materials. 2015. V. 48. PP. 222-225. https://doi.org/10.1016/j.optmat.2015.08.004.

8. Karaksina E.V., Kotereva T.V., Shiryaev V.S. Luminescence properties of core-clad $\operatorname{Pr}(3+)$-doped $\mathrm{Ge}-\mathrm{As}$-Se-Ga(In)-(I) glass fibers // Journal of Luminescence. 2018. V. 204. PP. 154-156. https://doi. org/10.1016/j.jlumin.2018.08.009.

9. Shiryaev V.S., Karaksina E.V., Kotereva T.V., Snopatin G.E., Velmuzhov A.P., Sukhanov M.V., Churbanov M. F. Core-clad $\operatorname{Pr}(3+)$ doped $\mathrm{Ga}(\mathrm{In})$-Ge-As-Se Class Fibers for Mid-IR Radiation Sources // Journal of Non-Crystalline Solids. 2020. V. 537. PP. 120026. https://doi. org/10.1016/j.jnoncrysol.2020.120026.

10. Conseil C., Shiryaev V.S., Cui S., Boussard-Pledel C., Troles J., Velmuzhov A.P., Potapov A.M., Suchkov A.I., Churbanov M.F., Bureau B. Preparation of high purity Te-rich Ge-Te-Se fibers for 5-15 mkm infrared range // Journal of Lightwave Technology. 2013. V. 31(11). PP. 1703-1707. https://doi.org/10.1109/JLT.2013.2257163.

11. Velmuzhov A. P., Sukhanov M.V., Shiryaev V.S., Churbanov M.F., Kotereva T. V., Zernova N. S., Fadeeva D. A. Preparation of Especially Pure Ge-Se Classes via Germanium Monoselenide for Mid-IR Fiber Optics // Optical Materials. 2018. V. 84. PP. 888-892. https://doi. org/10.1016/j.optmat.2018.08.029.

12. Karaksina E.V., Shiryaev V.S., Kotereva T.V., Velmuzhov A.P., Ketkova L.A., Snopatin G.E. Preparation of high-purity $\operatorname{Pr}(3+)$ doped Ge-As-Se-In-I glasses for active mid-infrared optics // Journal of Luminescence. 2016. V. 177. PP. 275-279. https://doi. org/10.1016/j.jlumin.2016.05.005.
13. Velmuzhov A.P., Sukhanov M.V., Plotnichenko V.G., Plekhovich A.D., Shiryaev V.S., Churbanov M.F. Preparation of REE-doped Ge-based chalcogenide glasses with low hydrogen impurity content // Journal of NonCrystalline Solids. 2019. V. 525. PP. 119669. https://doi.org/10.1016/j.jnoncrysol.2019.119669.

14. Romanova E., Korsakova S., Komanec M., Nemecek T., Velmuzhov A., Sukhanov M., Shiryaev V. Multimode chalcogenide fibers for evanescent wave sensing in the mid-IR // Multimode chalcogenide fibers for evanescent wave sensing in the mid-IR, IEEE Journal of Selected Topics in Quantum Electronics. 2017. V. 23(2). PP. 289-295. https://doi.org/10.1109/ JSTQE.2016.2630846.

15. Velmuzhov A.P., Sukhanov M.V., Kotereva T.V., Zernova N.S., Shiryaev V.S., Karaksina E.V., Stepanov B. S., Churbanov M.F. Optical fibers based on special pure $\mathrm{Ce}_{20} \mathrm{Se}_{80}$ and $\mathrm{Ge}_{26} \mathrm{As}_{17} \mathrm{Se}_{25} \mathrm{Te}_{32}$ glasses for FEWS // Journal of Non-Crystalline Solids. 2019. V. 517. PP. 70-75. https:// doi.org/10.1016/j.jnoncrysol.2019.04.043.

16. Pele A.L., Braud A., Doualan J.L., Starecki F., Nazabal V., Chahal R., Boussard-Plédel C., Bureau B., Moncorge R., Camy P. Dy ${ }^{3+}$ doped CeGaSbs fluorescent fiber at $4.4 \mathrm{mkm}$ for optical gas sensing: Comparison of simulation and experiment // Optical Materials. 2016. V. 61. PP. 37-44. https://doi.org/10.1016/j.optmat.2016.04.016.

17. Starecki F., Morais S., Chahal R., Boussard-Plédel C., Bureau B., Palencia F., Lecoutre C., Garrabos Y., Marre S., Nazabal V. IR emitting $\mathrm{Dy}^{3+}$ doped chalcogenide fibers for in situ $\mathrm{CO}_{2}$ monitoring in high pressure Microsystems // International Journal of Greenhouse Gas Control. 2016. V. 55. PP. 36-41. https://doi.org/10.org/10.1016/j.ijggc.2016.10.015.

18. Gattass R.R., Shaw L.B., Nguyen V.Q., Pureza P.C., Aggarwal I.D., Sanghera J.S. All-fiber chalcogenide-based mid-infrared supercontinuum source // Optical Fiber Technology. 2012. V. 18(5). PP. 345-348. https:// doi.org/10.1016/j.yofte.2012.07.003.

19. Dai S., Wang Y., Peng X., Zhang P., Wang X. and Xu Y. A Review of Mid-Infrared Supercontinuum Generation in Chalcogenide Glass Fibers // Applied Sciences. 2018. V. 8(5). PP. 707. https://doi. org/10.3390/app8050707.

20. Leonov S. O., Wang Y., Shiryaev V.S., Snopatin G.E., Stepanov B. S., Plotnichenko V.G., Vicentini E., Gambetta A., Coluccelli N., Svelto C., Laporta P., and Galzerano G. Coherent mid-infrared supercontinuum generation in tapered suspended-core As-Se fibers pumped by five-optical cycles Cr:ZnSe laser // Optics Letters. 2020. 45. PP. 1346-1349. https:// doi.org/10.1364/OL.386429.2.

\section{ОБНАРУЖЕНО ОБРАЗОВАНИЕ ЧЕТЫРЕХЦЕПОЧЕЧНОЙ ДНК}

Известно, что ДНК имеет форму двойной спирали. Однако в клетках обнаружены и четырехспиральные структуры, называемые С-квадруплексами ДНК. Используемый ранее для их обнаружения метод требовал либо

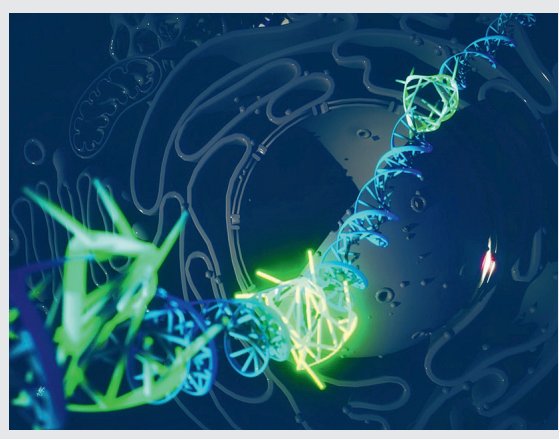

уничтожения клеток, либо использования высоких концентраций химических зондов для визуализации их образования, поэтому фактическое присутствие в живых клетках при нормальных условиях не отслеживалось. Для наблюдений in vivo исследовательская группа под руководством ученых Кембриджского университета изобрела флуоресцентный маркер, который может прикрепляться к G-квадруплексам ДНК живых клеток человека.

«Впервые мы смогли доказать, что ДНК с четверной спиралью существует в наших клетках как стабильная структура, созданная нормальными клеточными процессами", - заявил доктор Марко Ди Антонио, сотрудник химического факультета Имперского колледжа
Лондона. "Это заставляет нас переосмыслить биологию ДНК".

Авторы смогли доказать, что С-квадруплексы ДНК образуются и рассеиваются очень быстро, а формируются только для выполнения определенной функции. Если это происходит слишком долго, то они могут стать токсичными для нормальных клеточных процессов. Ученым нужны специальные зонды, чтобы видеть молекулы в живых клетках.

Новый зонд связывается с С-квадруплексами ДНК всего за миллисекунды, не влияя на их стабильность, что позволяет исследователям изучать поведение G-квадруплексов ДНК в их естественной среде без внешнего воздействия.

Источник: http://www.sci-news.com 